\title{
Becoming Full Open Access
}

The beginning of a New Year is the time when we all stop to evaluate what happened during the closing year, and think about what lies ahead for the new one.This assessment is traditionally the topic of the Journal of the Brazilian Chemical Society $(J B C S$ ) first Editorial every year.

For us, the year of 2016 marked the transition to full Open Access system, with the requirement that all authors of the $J B C S$ should contribute with page charges in order to meet the financial demand to maintain the Publishing Office and Journals of the Brazilian Chemical Society (this was accompanied by the other three major Journals published by PubliSBQ). This transition also happens at a time in which all the major scientific publishers, whether linked to Scientific Societies like us, or to private publishers, are going in the same direction. Our analysis is that this represents an irreversible change in the philosophy of Scientific publications in which supporting agencies will impose regulations to ensure that results from publicly funded research should be made freely available to all, regardless of their affiliation to Universities or Research Institutions, who traditionally subscribe to publication services. This is already true in many countries and it is vital that Brazilian Agencies take into account this new trend in order to allow that research grants include funds to support payment for page fees for the publication of results derived from these projects. Some even estimate that, overall, the open access system should be cheaper than keeping subscription to all Journals as in the current model. Moreover, authors should now focus in trying to divulge their results in Journals that provide full and open access, and also to escape from the predatory ones, paying careful attention to identify who is behind their Journal of choice.

An evaluation of the manuscript flow in the JBCS since the beginning of the full Open Access system indicates a decrease of around $40 \%$ in the number of submitted articles comparing to the same period of last year, but with a slow recovery for the latest months. This reduction was more prominent among submissions from abroad, and now the submissions from Brazilian authors account for around $60 \%$ of our total, in comparison to below $50 \%$ in previous years. More importantly, the quality of the submissions was kept, as indicated by a current rejection rate slightly smaller than previously. We need a longer period to allow for a better statistical analysis, but our inference is that the community of authors for the JBCS has understood and reacted positively to our Open Access policy.

One point that remains central to us is the latest trend of decrease for the JBCS impact factor, as measured by Thomson-Reuters. Incidentally, a similar trend is observed for our sister Journal, Química Nova. If we analyze IF trends for similar General Chemistry Journals published by Scientific Societies, our absolute values are not far, but only a few display the same descending trend. Many factors may be the cause for such a trend, but we are sure that it does not reflect a decrease in the quality of the results published by the JBCS, nor by Química Nova. The question then is why these articles are less cited than similar work published by the same group of authors in other Journals? This has been the subject of an earlier Editorial in the $J B C S,{ }^{1}$ and we still believe that our community should reflect on that seriously. If articles published in the Brazilian Chemistry Journals are not cited, we are neither giving the proper credit to, nor recognizing the quality of Science produced in Brazil. This is not just bad scientific practice, but "shooting ourselves in the foot" for undermining all the efforts taken in the last decades to consolidate strong Chemistry Journals in Brazil. It is time to change this scenario, therefore we call the attention of our colleagues to rethink the way they choose their reference papers.

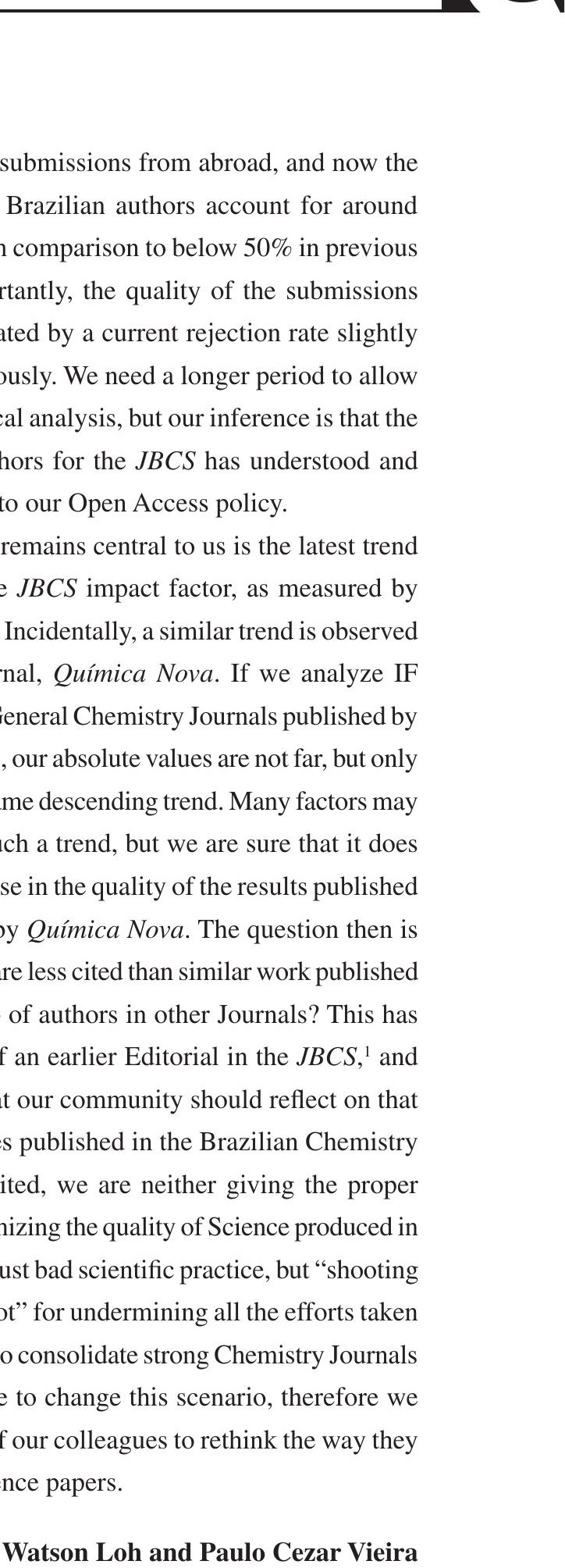
Editors of the Journal of the Brazilian Chemical Society

\section{Reference}

1. Nobrega, J. A.; Loh, W.; J. Braz. Chem. Soc. 2015, 23, 403. 